\title{
Specialist training for cardiothoracic surgery in the Nordic countries
}

Ari Mennander, MD, PhD, ${ }^{\mathrm{a}}$ Tomas Gudbjartsson, $\mathrm{MD}, \mathrm{PhD},{ }^{\mathrm{b}}$ Anders Jeppsson, MD, PhD, ${ }^{\mathrm{c}, \mathrm{c}}$ Vibeke Hjortdal, MD, $\mathrm{PhD},{ }^{\mathrm{e}}$ and Theis Tønnessen, $\mathrm{MD}, \mathrm{PhD}^{\mathrm{f}}$

\section{ABSTRACT}

Sweden, Denmark, Finland, Norway, and Iceland form the 5 culturally uniform Nordic countries. Each of the countries owns a high-standard tradition of individual steering in cardiothoracic education aiming at securing the needs and features of the local area. Indisputably, mastering a Nordic language and applying a highstandard individual steering in education ensure that a dedicated trainee is selected to the cardiothoracic program in accordance with the needs and features of the local area. (J Thorac Cardiovasc Surg 2020;159:1002-8)

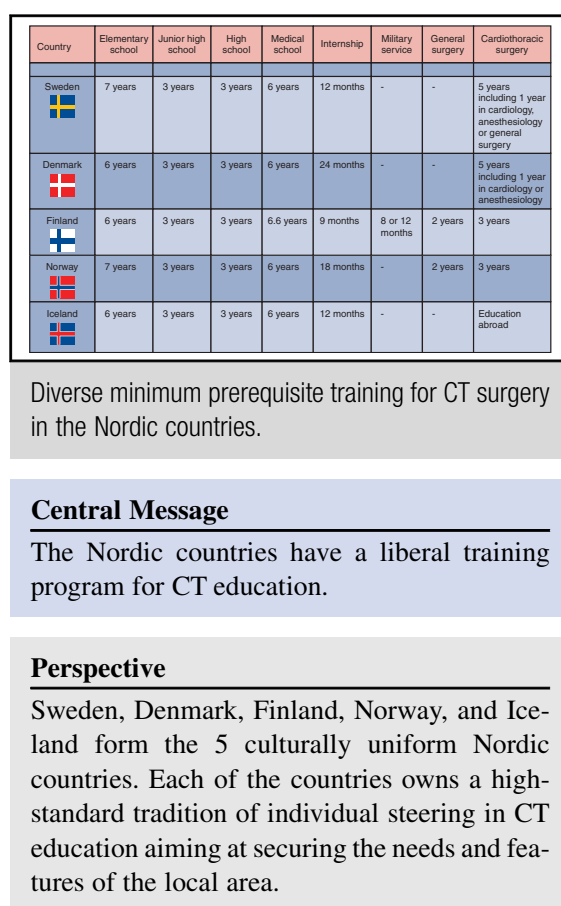

See Commentary on page 1009

\section{A BRIEF INTRODUCTION TO THE NORDIC COUNTRIES}

The overall population in the Nordic countries is 25 million inhabitants, with Sweden representing the largest

\footnotetext{
From the ${ }^{\text {a }}$ Tampere University Heart Hospital and Tampere University, Tampere, Finland; ' Department of Cardiothoracic Surgery, Landspitali University Hospital, Faculty of Medicine, University of Iceland, Reykjavik, Iceland; ${ }^{c}$ Department of Molecular and Clinical Medicine, Institute of Medicine, Sahlgrenska Academy, University of Gothenburg, Gothenburg, Sweden; ${ }^{\mathrm{d}}$ Department of Cardiothoracic Surgery, Sahlgrenska University Hospital, Gothenburg, Sweden; ${ }^{\mathrm{e}}$ Aarhus University Hospital, Aarhus, Denmark; and ${ }^{\mathrm{f} D e p a r t m e n t}$ of Cardiothoracic Surgery, Oslo University Hospital and University of Oslo, Oslo, Norway.

Funding received by the Competitive State Research Financing of the Expert Responsibility area of Tampere University Hospital, Tampere Finland.

Received for publication April 16, 2019; revisions received July 1, 2019; accepted for publication July 28, 2019; available ahead of print Oct 4, 2019.

Address for reprints: Ari Mennander, MD, PhD, Tampere University Heart Hospital, SDSKIR, Ensitie 4, PL 2000 Tampere, Finland (E-mail: ari.mennander@ sydansairaala.fi)

0022-5223/\$36.00

Copyright (c) 2019 by The American Association for Thoracic Surgery

https://doi.org/10.1016/j.jtcvs.2019.07.110
}

population of approximately 10.1 million. Denmark, Finland, and Norway have approximately 5.2 to 5.8 million inhabitants each, whereas Iceland has only 350,000 inhabitants in total. The combined area of the Nordic countries $(1,322,710$ square miles) would form the seventh largest nation in the world (Figure 1).

\section{Historical Landmarks of Cardiothoracic Surgery in the Nordic Countries}

The development of surgery in the Nordic countries mirrors in general the major medical achievements in Europe. The pioneer of Swedish surgery was Olof Acrel, who founded an early hospital in Sweden in 1752. More than 80 years later, in 1835, Karl Gustaf Lennander established the first surgical clinic in Stockholm. ${ }^{1}$ In 1877, Finnish surgeon Jacob August Estlander introduced thoracoplasty for chronic empyema, a method he developed that still bears his name. The first heart wound was operated on in 1895 


\section{Abbreviation and Acronym}

$\mathrm{CT}=$ cardiothoracic

by Norwegian surgeon Axel Hermansen Cappelen. In 1937, Finnish surgeon Per Edvin Alfred Nylander performed pulmonary lobectomy under local anesthesia. He was a pioneer in cardiothoracic (CT) surgery influenced by the ravaging world wars in Finland. In Stockholm, the early era of cardiac surgery as defined by the years during and after World War II between 1940 and 1960 benefited from encouraging progress experienced in general thoracic surgery. ${ }^{2}$ Swedish surgeon Clarence Crafoord operated on a persistent ductus arteriosus in 1941, after learning the technique during his stay in Boston and actively participating on research to purify heparin. He also met with John Heysham Gibbon and learned from his team about the first heart-lung machine. The first elective heart operation in Finland was a pericardectomy performed in 1945, but 7 years later CT surgery was officially established as a subspecialty in Finland. In 1954 , a myxoma of the heart was operated on in Sweden using for the first time a heart-lung machine. Ake Senning implanted the first pacemaker in 1958 and invented the Senning operation. Examples of further international contributions were fortified by Swedish cardiac surgeon Viking Olof Bjork, who collaborated with Donald Pearce Shiley and developed the Bjork-Shiley valve prosthesis in 1968.

\section{Socioeconomic Perspective in the Nordic Countries}

The Nordic countries are characterized by a highstandard Western-style of living. ${ }^{4}$ The average health status in the Nordic countries has improved in many respects over the last few decades, and life expectancy is among the highest in the world. ${ }^{5}$ Socioeconomic inequalities in health and well-being are closely monitored in the Nordic countries, as in any other modern welfare states committed to values of equality. ${ }^{6}$ Education in CT surgery is closely linked to the philosophy of preventive medicine; an increasing awareness of patient education and mentoring is being emphasized before and after surgery. ${ }^{7}$ Patients are invited to preoperative seminars on CT surgery.

\section{BACKGROUND ON CURRENT CARDIOTHORACIC SURGERY IN THE NORDIC COUNTRIES}

CT surgery in the Nordic countries is considered to be one unified medical specialty encompassing education for both cardiac and general thoracic surgery. Vascular surgery used to be included in this specialty until as late as the 1980s.

Every citizen in the Nordic countries may be identified and tracked according to his/her Social Security numbers for patient records. All university, area, and county hospitals are funded by counties that directly tax their inhabitants as a single-payer system. Hospitals are encouraged to participate in research projects that may use governmental grants for education and research. According to

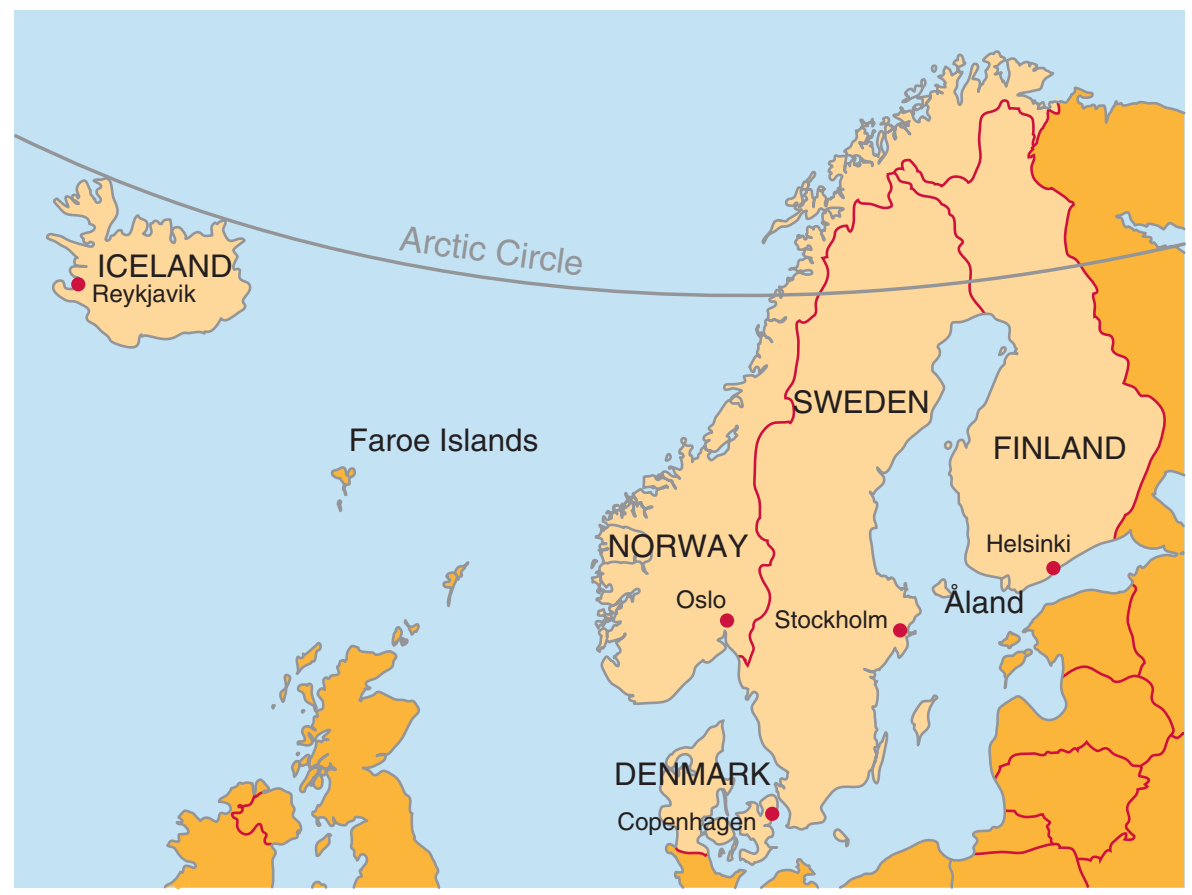

FIGURE 1. Representative map of the 5 Nordic countries (Sweden, Denmark, Finland, Norway, and Iceland) in order of population density. The capitals of the countries are marked. The Faroe Islands are part of Denmark, and Åland belongs to Finland. Areas not shown include Greenland and Svalbard, which are part of Denmark and Norway, respectively. 
socioeconomic welfare in the Nordic countries, health care including CT surgery is free for citizens. A small nominal fee (USD 10-20 per visit) may apply to outpatient and hospital care.

\section{Heart Surgery Registries}

Cardiac operations have been centrally registered for more than 20 years in the Nordic countries. Each Nordic country established its own national Heart Surgery Registry in the early 1990s. For example, the Swedish Heart Surgery Registry has had 100\% coverage in Sweden since $1992 .{ }^{8}$ The general thoracic surgery registry, THOR, covers all general thoracic surgery performed in Sweden, and SwedCon includes all congenital cardiac surgery in Sweden. Similar national general thoracic registries have now been established in the other Nordic countries.

\section{Hospital Structure and Estimated Numbers of Cases in the Nordic Countries}

Most of the inhabitants of Sweden, Finland, Norway, and Iceland reside in the Southern part of these countries, whereas the population density in Denmark is relatively uniform. The northern inner part of the Nordic countries, together with the whole of Iceland, has a relative low population density. ${ }^{9}$ These remote areas present a considerable challenge for providing equal management of surgical emergencies (Tables 1 and 2).

Sweden has 7 university hospitals and 1 area hospital performing cardiac and thoracic surgery. Pediatric cardiac surgery, adult congenital cardiac surgery, and cardiac and pulmonary transplantations are performed in 2 centers. In 2018, 5851 open operations on adult patients, approximately 500 open operations on children, 2526 general thoracic operations, and 140 cardiopulmonary transplantations were performed in Sweden alone. ${ }^{10}$

In Denmark, 4 university hospitals perform CT surgery and are qualified for the training of CT trainees. Approximately 2900 heart operations, 1200 lung cancer operations, 2000 operations for diagnostics and other surgical procedures, and 1200 operations for minor procedures are performed annually. ${ }^{11}$ Thoracic aortic operations and transcatheter stenting are performed in collaboration with surgeons, imaging specialists, and cardiologists. A perfusion school for the Nordic countries is located in Arhus, Denmark, but Finns do not attend because perfusion in Finland is exceptionally taught to selected cardiac anesthesiologists only. All perfusionists in Finland are CT anesthesiologists, which is an exception in the Nordic countries.

Finland is divided into 5 main hospital areas, each one centered by a university hospital that is responsible for the education in CT surgery provided in the country. Cardiac surgery is practiced only within the 5 university hospitals. Thoracic surgery is, in addition to the 5 university hospitals, performed in 8 central hospitals as well, although the centralization of the oncologic thoracic surgery procedures is under discussion. On an annual basis, there are 3550 open operations for adults and 600 operations for lung cancer. Endovascular treatment of thoracic aortic aneurysms involves 50 cases. There are 25 open operations annually on the descending thoracoabdominal aorta. A total of 300 congenital heart surgeries and approximately 150 esophageal operations are also performed annually. ${ }^{12}$

Norway has 4 university hospitals. There are 8 hospitals performing general thoracic operations in Norway. In 2018, there were 3799 open operations, including 258 operations performed in patients aged less than 18 years. Pediatric cases were all operated on in 1 single unit in Oslo. Cardiac and lung transplantations were performed in 59 patients, and there were 626 operations for lung cancer. ${ }^{13}$

One center performs all CT operations in Iceland. Cardiac and general thoracic procedures are performed by a team of 4 senior surgeons. Annually, between 200 and 250 open cardiac procedures are performed, including 10 pediatric procedures. Patients requiring advanced pediatric cardiac procedures or transplantations are sent to Sweden. In Iceland, all open procedures have been registered in a centralized database since the first case performed in June $1986 .^{14}$

Transcatheter aortic valve replacements are performed in all Nordic countries. In 2018, these included 1100 in Sweden, 500 in Denmark, 420 in Finland, 636 in Norway, and 20 in Iceland. Most likely, these procedures will increase in number in the Nordic countries as in many other Western countries. This will have an impact on the training for future CT surgeons who will also need to be familiar with catheterbased procedures.

Esophageal surgery is performed by gastrointestinal surgeons in Norway, Sweden, and Iceland, whereas in Finland and Denmark, these operations are also performed by CT surgeons. In both Denmark and Finland, surgery for esophageal perforations is performed in 100 patients yearly, of whom 20 undergo esophageal stenting. There are approximately 50 surgically operated esophageal tumors yearly in both these countries.

The division of cardiac, general thoracic, and congenital CT surgery is at the discretion of each of the university hospital that works independently in a specified area of the country. However, congenital CT surgery is concentrated in only 1 center in each country ( 2 in Sweden).

\section{OVERVIEW OF THE SPECIALIZATION}

According to the legal recommendations in the Nordic countries, working for more than 40 hours per week (excluding time on-call) is not allowed, making surgical education challenging. Effective education demands voluntary dedication outside working hours. The trainee is expected to participate in meetings both nationally and internationally, including special courses on skills training 
TABLE 1. Number of surgeons and trainees in the Nordic countries in relation to population and total number of cardiothoracic cases*

\begin{tabular}{lcccc}
\hline Country & Population/million & $\begin{array}{c}\text { No. of CT } \\
\text { surgeries }\end{array}$ & $\begin{array}{c}\text { No. of } \\
\text { surgeons }\end{array}$ & $\begin{array}{c}\text { No. of } \\
\text { trainees }\end{array}$ \\
\hline Sweden & 10.1 & 9400 & 101 & 15 \\
Denmark & 5.8 & 4800 & 58 & 10 \\
\hline Finland & 5.6 & 4900 & 56 & 8 \\
Norway & 5.2 & 4800 & 52 & 5 \\
\hline Iceland & 0.3 & 380 & 4 & 0 \\
\hline
\end{tabular}

$C T$, Cardiothoracic. ${ }^{*}$ Transcatheter-based procedures not included.

using cadavers and experimental animal models. Collective responsibility of the treatment path of each patient is emphasized during training and among colleagues in the Nordic countries. The successful completion of training in CT surgery is considered to be a goal-oriented achievement rather than time-based education. The competence of all CT surgeons is closely followed. Traditionally, there is no fixed schedule or planned rotation for the trainee.

\section{Prerequisite Training}

The medical faculties in the Nordic countries are all financed by the government, and currently no tuition fees apply. After 12 years of school including 3 years in high school, the graduate applies for medical school. Grades from schools or a national academic test and a university entry test determine successful admission to medical school. The directional and minimum requirements of training for CT surgery are not homogeneous in the Nordic countries (Table 3). In Sweden, after a 6-year medical school education, a 12-month internship period is expected for full medical license before surgical training may be commenced. In Denmark, after a 1-year internship, another 1-year internship in CT surgery is required before entering a CT training program. In Finland, after a 6-month internship included in medical school, a 9-month internship as a general practitioner is obligatory, and every male citizen is expected to join the national army for 6 to 12 months of military service; military service for female Finnish citizens is voluntary. If the serviceman is nominated officer candidate during military service after medical school, a 6-month internship in the Finnish army serving as a medical officer is possible. In Norway, after a 12-month internship, another 6-month internship as a general practitioner is required. In Iceland, the medical internship is 12 months. In practice, after at least 2 years of working, but often after 4 to 8 years, depending on the university schedule and the proficiency of the candidate, the candidate may choose to apply for a training program including $\mathrm{CT}$ surgery.

\section{Selection for Cardiothoracic Surgery}

Currently, selection for the specialty has been unsystematic, and applications have been possible by completing paper forms to an individual university hospital. Each hospital trains its own future specialists. The number of applicants varies each year, but 5 to 10 applicants aspire to each training position, and the positions are filled every year. It appears that the applicants have less surgical competence than earlier, because many apply immediately after internship without any basic surgical skills. Earlier, the trainees needed to have basal training in general surgery before they were accepted as trainees in CT surgery. Nowadays, it is possible to apply directly to CT training after internship. The individual mentor is very important to secure adequate training that continues after formally achieving the license for CT surgery.

\section{Cardiothoracic Surgery Training Positions and Accreditation}

In Sweden, the number of training programs is decided by each center, depending on the areal need. The trainees are appointed after a mandatory 12-month internship (containing internal medicine, surgery, psychiatry, and general medicine) after medical school. Often it is the case that most trainees have also worked 6 to 12 months at a CT surgery center before being appointed as trainees. The training program is 5 years in length and generally includes 4 years of CT surgery, 6 months of anesthesiology, and 6 months of

TABLE 2. Directional numbers of cardiothoracic cases in the Nordic countries in 2018

\begin{tabular}{|c|c|c|c|c|c|}
\hline & Sweden & Denmark & Finland & Norway & Iceland \\
\hline Adult cardiac & 5851 & 2900 & 3550 & 3541 & 240 \\
\hline Adult aortic & 309 & 200 & 220 & 263 & 22 \\
\hline Pediatric cardiac & 500 & 250 & 250 & 258 & 10 \\
\hline Adult congenital & 50 & undefined & 30 & undefined & undefined \\
\hline Transplant & 140 & 51 & 65 & 59 & 0 \\
\hline Lung/thoracic & 2526 & 1200 & 600 & 626 & 100 \\
\hline Esophageal/foregut & $\begin{array}{c}\text { Not performed by } \\
\text { CT surgeons }\end{array}$ & 150 & 150 & $\begin{array}{c}\text { Not performed by } \\
\text { CT surgeons }\end{array}$ & $\begin{array}{c}\text { Not performed by } \\
\text { CT surgeons }\end{array}$ \\
\hline
\end{tabular}

$\overline{C T}$, Cardiothoracic. ${ }^{*}$ Transcatheter-based procedures not included. 
TABLE 3. Minimum prerequisite training for cardiothoracic surgery and pathways for board certification in the Nordic countries

\begin{tabular}{|c|c|c|c|c|c|c|c|c|}
\hline Country & $\begin{array}{l}\text { Elementary } \\
\text { school }\end{array}$ & $\begin{array}{l}\text { Junior high } \\
\text { school }\end{array}$ & $\begin{array}{l}\text { High } \\
\text { school }\end{array}$ & $\begin{array}{c}\text { Medical } \\
\text { school }\end{array}$ & Internship & $\begin{array}{c}\text { Military } \\
\text { service }\end{array}$ & $\begin{array}{l}\text { General } \\
\text { surgery }\end{array}$ & CT surgery \\
\hline Sweden & $7 y$ & $3 y$ & $3 y$ & $6 y$ & $12 \mathrm{mo}$ & - & - & $\begin{array}{l}5 \text { y including } 1 \text { y in } \\
\text { cardiology, anesthesiology, } \\
\text { or general surgery }\end{array}$ \\
\hline Denmark & $6 y$ & $3 y$ & $3 y$ & $6 y$ & $24 \mathrm{mo}$ & - & - & $\begin{array}{l}5 \text { y including } 1 \text { y in cardiology } \\
\text { or anesthesiology }\end{array}$ \\
\hline Finland & $6 y$ & $3 y$ & $3 y$ & $6.6 \mathrm{y}$ & $9 \mathrm{mo}$ & 6 to $12 \mathrm{mo}^{*}$ & $2 y$ & $3 y$ \\
\hline Norway & $7 y$ & $3 y$ & $3 y$ & $6 y$ & $18 \mathrm{mo}$ & - & $2 y$ & $3 y$ \\
\hline Iceland & $6 y$ & $3 y$ & $3 y$ & $6 y$ & $12 \mathrm{mo}$ & - & - & Education abroad \\
\hline
\end{tabular}

$C T$, Cardiothoracic. ${ }^{*}$ Military service is compulsory for men and voluntary for women, and duration is 12 months for officers and 6 months for nonofficers. Military refresher courses are organized on demand.

cardiology. Instead of anesthesiology and cardiology, some trainees may have 6 to 12 months of general surgery. The curriculum of the training program including the number of operations required has been jointly decided by the Swedish Society of CT Surgery and the Swedish National Board of Health and Welfare. On average, approximately 2 to 4 candidates complete their training and become board-certified CT surgeons annually. As of today, the trainees who complete the required 5 years of training and successfully complete a necessary number of courses and operations in accordance with the program may be board-certified as CT surgeons. A recommendation must be approved by the head of the department. The Swedish National Board of Health and Welfare issues the final approval of the trainee.

Training in Denmark adheres much to the system in Sweden. The number of training programs is decided by each center, depending on the areal need. The trainees are appointed after a mandatory 12-month internship (containing internal medicine, surgery, psychiatry, and general medicine) after medical school, and most trainees have also worked 12 months at a CT surgery center before being appointed as trainees officially for CT. The duration for CT training in Denmark is 5 years and generally includes 4 years of CT surgery, 6 months of anesthesiology, and 6 months of cardiology. Each trainee is supervised by a nominated personal mentor.

The current Finnish CT training program complies in practice with the selection system and approval of the trainee described for Sweden. Starting from next year, the 5 national Finnish universities will continue to select the trainee based on vacancy, but the Ministry of Social Affairs and Health will centrally guide the universities in selecting the trainee according to the need for future CT surgeons in the specific specialty area governed by the university. Selection will occur in accordance with an initial scoring of the student, interview, and test period. The initial scoring will dependent on previous working experience and academic achievements, such as the applicant's scientific publications.

The 4 Norwegian university hospitals have dedicated positions for CT training. These positions are assigned on a 3-year basis. Trainees who successfully complete the required 3 years of training, including a necessary number of courses and operations in accordance with a given list, may be approved by the head of the department to apply for board certification of CT surgery. On average, approximately 1 to 3 candidates complete their training and become board-certified CT surgeons on an annual basis in Norway. Up to this date, an additional board-certified specialty in general surgery has been required for the specialty in CT surgery.

There is no formal training in CT surgery in Iceland. All Icelandic CT surgeons are trained overseas, mostly in Sweden and the United States.

\section{Required Operative Experience}

In Sweden and Norway, the required operative experience is monitored according to an operation list that consists of specific cardiac (20 aortic valve replacements, 55 coronary artery bypass, and 5 mitral valve operations) and noncardiac (20 anatomic lung resections in addition to thoracoscopies and mediastinoscopies) operations, as well as other minor surgeries, such as inserting counterpulsation cannulas and repairing arteriovenous fistulas. The minimum number of required cases that the trainee needs to perform as the principle surgeon under the surveillance of the mentor is directional, and most trainees perform well above the minimum of the required curriculum. In Denmark and Finland, the operative experience is dependent on the center and whether the trainee is aiming for mostly thoracic or cardiac surgery. The trainee is evaluated by their mentor. The trainee may perform up to 100 cardiac and 100 thoracic cases. The trainee is also responsible for on-calls, together with a senior staff member. The aim of the mentor is to educate the trainee as a full staff member of the hospital in question. 


\section{Required Academia}

The Nordic academic system encourages training parallel to medical and surgical training. The $\mathrm{PhD}$ program usually requires 4 to 6 years of research at a medical faculty, and approximately one-quarter (less in Denmark) of Nordic physicians obtain a PhD degree. ${ }^{1}$ Surgical trainees are expected to work in education, research, and clinical practice. The $\mathrm{PhD}$ degree is often regarded a prerequisite in university and affiliated hospitals. ${ }^{1}$

\section{Assessment of Trainees}

The Swedish goal-oriented education states that the trainees should improve their ability to make independent and sound decisions concerning issues involving medical ethics; acquire knowledge on general health care; participate in departmental activities related to organizational planning, quality improvement, and financial management; acquire knowledge on leadership; act for the benefit of preventive medicine; develop teaching skills; and acquire knowledge on new technology.

\section{Current Requirements of Board Certification}

In Sweden, the local head of the department recommends the trainee to a board consisting of all the heads of CT centers in Sweden. If the board accepts the application, the trainee can apply for board certification at the Swedish National Board of Health and Welfare.

In Denmark, the senior colleagues oversee the progression of the candidate. The final evaluation of the candidate is held at the areal consultant meeting by the end of the entire training period. Failing on the evaluation may lead to an additional 6 to 12 months of rotation.

Finnish CT surgeons are required to pass a national written examination, which is provided in Finnish, Swedish, or English in accordance with the preference of the trainee. Among the Nordic countries, only in Finland one needs to pass a written examination that is graded by the national board team that includes a representative from each of the 5 universities to obtain final approval for board certification. The areal university oversees for the accreditation of the trainee after successful accomplishment of the training program and written examination, after which the trainee applies for final approval for board certification from the Finnish National Board of Health and Welfare.

In Norway, after the candidate has completed the formal requirements, she/he submits an application for approval to the Specialty Committee, which consists of 5 CT surgeons selected by the Norwegian Association for CT Surgery on behalf of the Health Authorities overseeing the certification of the surgeons.
The Icelandic Health Government has a special committee that oversees the licensing of Icelandic CT surgeons, and the requirements are similar to those in Sweden.

Because a prerequisite is to speak a Nordic language fluently, there are few foreigners in the CT training programs in the Nordic countries. Fellowships may be offered for foreign students in a Nordic country. On the other hand, all Nordic countries are options for those who are proficient in a Nordic language (Swedish, Danish, Norwegian, and Icelandic). Some English-speaking countries, such as the United Kingdom, the United States, and Canada, may be other options. Finland is rarely an option because of the abstruse Finnish language, even though Swedish is an official language in Finland. The Nordic countries entitle all surgeons licensed in their own country to practice freely in all other Nordic countries and the European Union. The candidates often prefer to choose another specialty instead, if education in CT surgery is not possible in a Nordic country.

Most of the trainees in the Nordic countries receive their complete training in their own country, and usually only sporadic visits to other countries are carried out if the hospital desires an implementation of a new method or experience. Practically, it takes 5 to 10 years to be acknowledged as a senior CT surgeon after board certification. All surgeons in turn take responsibility of all patients at the center during ward rounds and on-calls. CT surgery in the Nordic countries is a lifelong apprenticeship that is best implemented in a teamwork fashion. The cardiologists of the hospital usually do not refer patients to a specific surgeon but to the surgical staff members as a whole who share the patients. The quality of surgery and treatment is considered equal among every hospital practicing CT surgery in the Nordic countries.

\section{CHALLENGES}

As observed in other Western countries, CT surgery aims at less-invasive approaches in the Nordic countries. Lung cancer may be treated by nonsurgical approaches, such as the use of stereotactic therapy. Economic factors may direct for less-expensive procedures. The training programs aim at keeping the future CT specialist working at the training university hospital.

\section{Future Endeavor of the Selection Process}

Planning for the national requirements of education with regard to specialties has been adapted from experience gained using international contacts, including the Northern countries in general, Canada, the United Kingdom, and Australia. It is apparent that the strong role of universities 
in planning for education is a peculiarity in Finland and Canada compared with many other countries. The aim is to secure safe and adequate quality for the requirements of the specialty concerned.

\section{CONCLUSIONS}

The selection of the candidate is challenging in the Nordic countries, which encompasses similar-minded countries with similar socioeconomic backgrounds. However, well-known Western virtues such as cultural diversity, respect of historical facts, and political freedom favor individual Nordic countries to decide for themselves on a governmental basis about education in CT surgery.

\section{Conflict of Interest Statement}

Authors have nothing to disclose with regard to commercial support.

\section{References}

1. Hamberger B. Surgery in Sweden. Arch Surg. 1998;133:323-6.

2. Radegran K. The early history of cardiac surgery in Stockholm. J Card Surg. 2003; 18:564-72.

3. Björk VO. The development of the Björk-Shiley artificial heart valve. Clin Cardiol. 1984;7:3-5.

4. Palosuo H, Koskinen S, Lahelma E, Kostiainen E, Prättälä R, Martelin T, et al. Health Inequalities in Finland. Trends in Socioeconomic Health
Differences 1980-2005. Ministry of Social Affairs and Health Publications 2009:9.

5. Jörgensen TSH, Fors S, Nilsson CJ, Enroth L, Aaltonen M, Sundberg L, et al Ageing populations in the Nordic countries: mortality and longevity from 1990 to 2014. Scand J Public Health. 2018;47:611-7.

6. Dalén M, Ivert T, Holzmann MJ, Sartipy U. Household disposable income and long-term survival after cardiac surgery: a Swedish nationwide cohort study in 100,534 patients. J Am Coll Cardiol. 2015;66:1888-97.

7. Veronesi G, Tunstall-Pedoe H, Ferrario MM, Kee F, Kuulasmaa K, Chambless LE. Combined effect of educational status and cardiovascular risk factors on the incidence of coronary heart disease and stroke in European cohorts: implications for prevention. Eur J Prev Cardiol. 2017;24:437-45.

8. Jernberg T, Jernberg T, Attebring MF, Hambraeus K, Ivert T, James S, et al. The Swedish web-system for enhancement and development of evidence-based care in heart disease evaluated according to recommended therapies (SWEDEHEART). Heart. 2010;96:1617-21

9. Grunfelder J, Rispling L, Norlen G. State of the Nordic region 2018. Theme 1: demography. Nordic Council of Ministers. 2019

10. Swedish cardiac surgery registry. Swedeheart Annu Rep. 2018

11. Özcan C, Juel K, Lassen JF, von Kappelgaard LM, Mortensen PE, Gislason G. The Danish heart registry. Clin Epidemiol. 2016;8:503-8.

12. Rellman J. Estimation of the need of education in medical subspecialities in Finland until 2030. Social and Health Ministry Reports. 2016:57.

13. Norwegian Registry for Cardiac Surgery In Collaboration With Norwegian Association for Cardiothoracic Surgery. Heart surgery in Norway. Norsk Hjertekirurgiregister. 2018.

14. Matthiasson P. Landspitali. Hospital Statistics and Accounts; 2016.

Key Words: specialist training, cardiothoracic surgery, education, Nordic countries 